\title{
Decision Making in the Marine Expeditionary Force (MEF) Combat Operations Center
}

\author{
Gary Klein \\ Klein Associates Inc. \\ 1750 Commerce Center Blvd North \\ Fairborn, $\mathrm{OH} 45324$ \\ Phone: 937-873-8166 \\ FAX: 937-873-8258 \\ E-mail: gary@klein-inc.com \\ John Schmitt \\ 2801 Valley Brook Drive \\ Champaign, IL 61821 \\ Phone: 217-356-8806 \\ FAX 217-356-0369 \\ E-mail: schmittzu@earthlink.net \\ Michael J. McCloskey \\ Klein Associates Inc. \\ 1750 Commerce Center Blvd North \\ Fairborn, $\mathrm{OH} 45324$ \\ Phone: 937-873-8166 \\ FAX: 937-873-8258 \\ E-mail: mike@klein-inc.com \\ Jennifer Phillips \\ Klein Associates Inc. \\ 1750 Commerce Center Blvd North \\ Fairborn, $\mathrm{OH} 45324$ \\ Phone: 937-873-8166 \\ FAX: 937-873-8258 \\ E-mail: jenni@klein-inc.com
}

\begin{abstract}
This study examined the cognitive requirements of the Marine Expeditionary Force (MEF) Combat Operations Center (COC) ${ }^{1}$. The MEF is a planning and decision-making organization that directs the activities of subordinate units such as divisions and air wings, and serves as a liaison with higher headquarters. A team of researchers attended a series of MEF exercises over a period of several years, conducting observations and interviews.
\end{abstract}

\footnotetext{
${ }^{1}$ This research was performed under contract N66001-96-C-7013 for the Space and Naval Warfare Systems Center, San Diego, CA.
} 
We identified several cognitive requirements: building and maintaining situation awareness, planning and decision making, information management, and providing top-level guidance. For each, we determined what was difficult about carrying out these functions within the MEF, and we identified several areas where we believe the MEF could improve. Our conclusion was that the MEF was successful at least as much because of the expertise of its staff as because of the procedures it had in place. Some of these procedures were counterproductive, such as an emphasis on deliberate planning over a dynamic planning of a more reactive nature. We also suggested some areas where the MEF needed more procedures, such as the management of Battle Damage Assessment data.

\section{Introduction}

This paper describes some of the cognitive challenges facing the commander and staff in the Marine Expeditionary Force (MEF) Combat Operations Center (COC). The purpose of this work was to provide the Marines with a better sense of the decision making and planning that goes on in the MEF, as a basis for improving performance. We had conducted a previous study for the U.S. Marine Corps [Klein et al., 1996] in which we examined the decision making of the regimental COC. The USMC requested that a parallel effort be conducted for the MEF. This paper presents the findings of that effort.

The MEF is in some ways analogous to an Army corps. The MEF commands divisions and air units, and serves as a liaison with other corps-level entities. In a large-scale mission, the MEF commander might report to the Ground Component Commander, to the Commander in Chief (as happened in Desert Shield/Desert Storm), the Commander of the Joint Task Force (if the MEF is part of a JTF) or the Naval Component Commander (if the MEF is operating as part of the fleet, e.g., for an amphibious operation).

The MEF is a command post. Like all command and control entities, it has to control events (figure out what needs to be done to bring about desired outcomes) and command troops (provide them with guidance and coordination). The Marines have determined the types of tasks that the MEF needs to perform. This study looked at the cognitive requirements for accomplishing those tasks.

We collected data on the MEF functions over a range of exercises. We observed and conducted interviews at three Phase III rotations, one Phase II exercise, and one Ulchi Focus Lens (UFL) exercise. The Phase II exercise was designed to provide practice in planning for the mission that would be executed during Phase III. Thus, Phase II was purely a planning exercise, whereas Phase III combined planning with execution. UFL was a larger scale coalition exercise conducted in Korea.

The observations were centered around the Current Operations (Current Ops) section (the nucleus of the Battle Coordination Center, or BCC), the Future Operations (Future Ops) section, the Future Plans section, and the Force Fires section. These form the core of MEF command and control (see Figure 1). The stated process is for the Future Plans group to identify the issues that will be relevant for the future and to prepare concept plans well in advance. Working from this concept plan, the Future Ops section is supposed to generate the necessary execution documents 
for the next phase of the operation. These include an operation or fragmentary order and other supporting documents such as adding targeted areas of interest (TAIs), named areas of interest (NAIs), which are presented in the Decision Support Matrix and the Decision Support Overlay. The Current Ops section in the BCC is engaged in executing the current battle, putting the detailed plan into effect. Unlike other aspects of operations, which are handled by time horizon according to the Future Plans/Future Operations/Current Operations model, fires are handled functionally, with the Force Fires section handling both the planning and execution of Fire Support.

\section{Deliberate Planning}

(a) Conceptual Planning

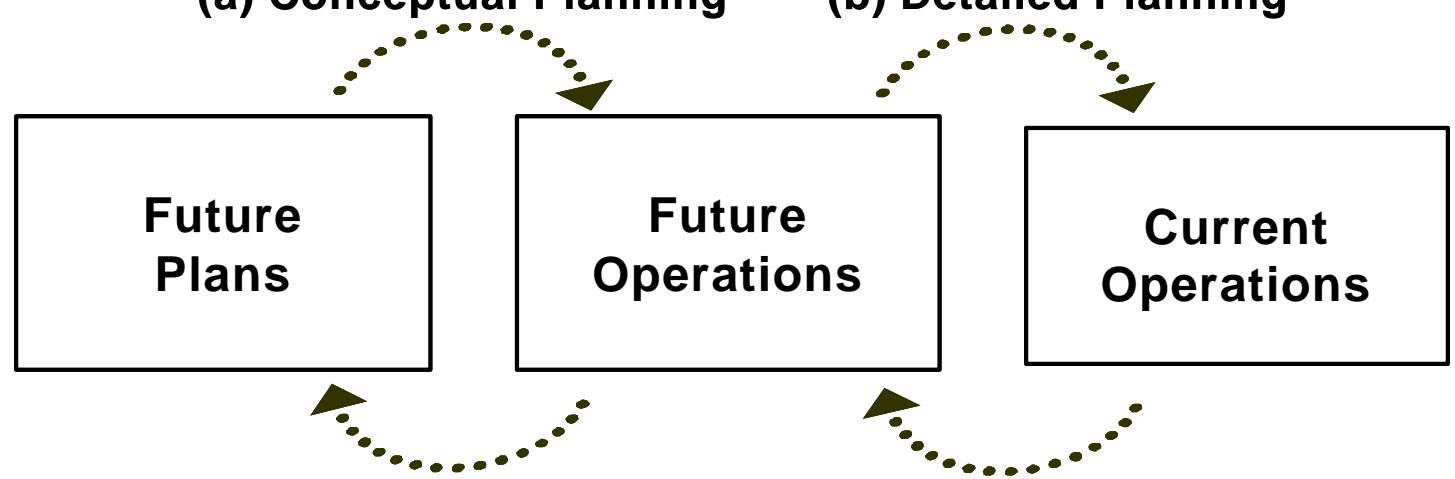

(d) Conceptual Replanning

(c) Detailed Replanning

\section{Dynamic Planning}

Figure 1. MEF planning flow.

We also observed at the logistics group, the intelligence group, and at the divisions and air units subordinate to the MEF. In all cases, the observers identified cognitive demands, studied the reasons why critical decisions were difficult, examined potential sources of errors, and tried to establish the strategies used by experienced command post personnel. We did not look at other issues such as leadership, morale, motivation, etc., but focused only on cognitive functions.

\section{The Cognitive Demands of the MEF: An Overview}

As shown in Table 1, the job of the MEF is (a) to form an understanding of what is happening (i.e., build situation awareness) and, (b) to figure out what to do about it (i.e., make plans and decisions). If the MEF carries out these functions well, its combat elements are more likely to succeed. However, in order to carry out these functions, the MEF also (c) needs to manage itself as any organization does. It needs to ensure that information management is effective so that relevant messages reliably get to their destination. Finally, the MEF needs (d) to ensure that its staff members and subordinate elements have guidance about their roles and functions.

These four functions are listed in Table 1. These functions appear to be the critical ones, and they are common to all command posts, both military and non-military. The functions are essentially cognitive ones. They refer to the way a command post "thinks." We refer to all of these functions together as "cognitive demands." 
Table 1

Cognitive Functions of Command Posts

(a) Building and maintaining situation awareness (SA)

(b) Planning and decision making:

Deliberate planning

Dynamic planning

(c) Information management:

Distributing information

Seeking information

(d) Guidance:

Provide top sight and direction

Clarify roles and functions

The MEF is a planning organization as opposed to an execution organization. We were told this repeatedly even before we began our study. In order to make a difference, the MEF must focus its cognitive energies well into the future, shaping conditions advantageously for the units that will actually execute the mission. Our project tried to find out what makes this difficult and what kinds of problems the MEF runs into.

In the exercises we watched, the MEF was successful in performing these functions, but the success was often due to the quality of personnel rather than the procedures they were following. Some of the primary strengths of the MEF are the dedication, experience, and flexibility of the Marines working there. The Marines we observed were highly goal-oriented, and their team dynamics let them adapt to situations in order to achieve success.

This is not a minor point. It is not clear to us that the quality of personnel is appropriately recognized. One of the weaknesses of the MEF was in the cumbersome procedures that often got in the way. And one reason for these procedures may be a lack of confidence in the Marines. One of the justifications we repeatedly heard for the procedures was that they ensure reasonable and predictable performance from everybody, even if they inhibit the talented. The procedures sometimes seemed like an attempt to substitute a series of steps, which could be reliably performed each time, for the skills of the Marines, which could not always be relied on. One of the topics we discuss throughout this report is the need for a proper balance of procedures. To some extent, procedures are invaluable. Without them, organizations have to waste valuable time reinventing the wheel. However, procedures can be over-specified, and then they can get in the way of effectiveness.

In the next sections, we go into detail about each of the cognitive functions listed in Table 1, describing why it was hard and the strategies we observed, and what kinds of errors we found. 


\section{Building and Maintaining Situation Awareness (SA)}

The most basic cognitive demand is to build and maintain an awareness of events that occurred. The MEF staff members have to accumulate data and reports from different sources and formulate a sense of what is going on, for both their own Marines and attached units, and for the enemy. The enemy picture is developed by the intelligence section, but we saw the BCC analysts making their own interpretations of what the enemy was up to. (See Table 2.)

Table 2

Cognitive Demands of Building and Maintaining Situation Awareness

\begin{tabular}{|c|c|c|}
\hline Why Difficult & $\underline{\text { Weaknesses }}$ & $\underline{\text { Strategies }}$ \\
\hline $\begin{array}{l}\text { Long-range vs. immediate } \\
\text { needs }\end{array}$ & $\begin{array}{l}\text { Over-specifying details } \\
\text { Over-proceduralizing }\end{array}$ & $\begin{array}{l}\text { Future Plans and Future } \\
\text { Ops cells }\end{array}$ \\
\hline Uncertainty & Disconnects between cells & Battlespace Shaping \\
\hline Need to set preconditions & Inefficiencies in Future Ops & Matrix (BSM) \\
\hline Safety & Lack of resources in Future Ops & \\
\hline $\begin{array}{l}\text { Lack of feedback regarding air } \\
\text { missions }\end{array}$ & $\begin{array}{l}\text { Limited focus on Future Ops } \\
\text { Focus on } B C C \text { crowds out }\end{array}$ & \\
\hline $\begin{array}{l}\text { Constraints of air planning } \\
\text { cycles }\end{array}$ & $\begin{array}{l}\text { Future Ops } \\
\text { Too many cells }\end{array}$ & \\
\hline
\end{tabular}

Building SA is not simply a matter of having good maps and visual aids. The command post staff has to derive inferences about the dynamics of the situation. This means going beyond the data, to notice trends, build expectancies, spot anomalies (violations of expectancies), and see leverage points that are opportunities to take advantage of. Logistics needs to project utilization rates. Operations needs to project rates of progress. Intel needs to project enemy movements. Fires needs to project target priorities and opportunities. The inferences include keeping track of who is doing what, and particularly what the enemy is currently doing and is projected to do. The MEF needs to synthesize the data and messages in order to gain this type of functional understanding.

Thus, the Future Ops cell needs to provide an overview of projected operations to the targeting boards, so they can do their planning. For an Air Tasking Order (ATO), where the developers are planning 48 hours out, the Future Ops cells need to tell them where the friendly assets are likely to be. Future Ops also tries to provide G2 with constraints, such as the fact that the ceilings may be below $\mathrm{X}$ feet two days into the future, so that certain munitions cannot be used.

During one MEF exercise (MEFEX), there was an unexpected enemy attack from the north. However, the MEF was able to pick up the early signs and anticipate this attack in time to prepare for it. The exercise started with the enemy about to initiate a major action not anticipated by the Intel that had been provided. Less than an hour into the exercise the G3 Analyst, the G2 Senior Watch Officer, and the Force Fires officer had all independently sensed the situation was 
different than expected. The Analyst was suspicious because of a single report of an enemy mechanized brigade moving during daylight, something they never did, which made him suspect the enemy was on an accelerated time schedule and was getting ready to attack. This was hardly conclusive evidence, but it turned out to be right, including his estimate of where the main attack would come. (This officer repeated the same skill based on minimal information several more times during the exercise.) The less-experienced technician had just noted the data, but this Analyst saw the implications, that an important attack was getting ready to kick off. The G2 Senior Watch Officer became suspicious, not by any events, but by a non-event. The rate of enemy messages had suddenly declined. This looked like the enemy was maintaining radio silence. In all, about three people in the BCC noticed different signs of an attack, and when they compared notes, they realized they needed to sound an alarm. They passed this alarm to Future Ops, as shown in part (c) of Figure 1, to produce a detailed plan for countering the threat; this exemplified the bottom-up tasking that frustrated the Future Ops cell.

The MEF has explored a number of strategies for improving the way it builds and maintains SA. One is the layout of the BCC itself, removing barriers between the operations side and the intelligence side, to foster a freer flow of information. This worked, and was very useful. In an operational setting, the need to shield some of the intelligence stations and maintain security might require alterations, but the general concept was appreciated. A second strategy was the use of home pages. These appear to have good potential, but they come at a cost - the personnel cost of creating and maintaining these home pages. At the most recent MEFEX we attended, the G2 estimated that he needed two full-time and one part-time staff members just to keep the home pages current and running. Additional technologies were also being studied, with the MAGTF Staff Training Program (MSTP) taking the lead with much of these. One technology mentioned in this regard was the use of the Message Dissemination System (MDS), which would let people screen their messages independently, for example, by sender and subject, which is a useful filter. One staff member observed that with the MDS, he could go into all the sitreps, and gain more situation awareness than from the Commanding General (CG) briefs.

The Army's experience was that an intelligence specialist could not always see the implications the way a technical specialist could, and both were needed. However, this strategy required additional staffing that may not be available to the MEF. To substitute, we found that the MEF was relying on informal connections, providing the Analysts and others in the BCC with the data that allowed them to make inferences, rather than just presenting interpretations and conclusions and not describing the basis for these. One strategy that seemed useful in deriving inferences was to use teams to interpret the data coming in. Thus, the Army's 101st relied on two-person teams, pairing an Intel person with someone from a different specialty (maneuver, logistics, artillery, etc.) depending on the type of data.

Example: Early in a MEFEX there were reports of an enemy attack in the north (as mentioned above). The intelligence specialist determined that the attack was being made by unit XXX. However, the Analyst in the BCC looked at the map and realized that there was no way that unit XXX could move so quickly from the west. He concluded that the attack must be from a new unit from the north. He explained that, as a "grunt," he had a different feel for equipment, terrain, and movement than the Intel Specialist. 
Later on, the Intel Specialist determined that the enemy was still advancing. However, the Analyst again disagreed. He saw no signs of advance from the key units of the enemy. The units that were advancing were a homegrown militia, and not very good. To him, these were not the units he would use to lead an assault. So he judged that they were a screen, to cover a withdrawal.

\subsection{Difficulties in Building and Maintaining Situation Awareness}

One difficulty was the inescapable uncertainty that makes up the fog of war. Another is the flip side of uncertainty: the crush of information that is available. If a Marine in the MEF did nothing more than read every message, study every sensor input, search for every possible relevant data element, he/she would have no time to do anything other than serve as an information sink. Thus, because of the way email works, it is hard to tell which emails are important without reading all of them. The use of groups in email looked like a good solution but had become abused. The MEF staffers received lots of extra mail that was not particularly relevant, but once a Marine is on a list, he got everything from that group. Somehow, they had to prioritize the messages, figure out which to study, which to save, which to route, and who to route it to. Somehow, they had to filter the messages, selectively attending to the important ones, and ignoring the others. They had to determine whether to send information to reactive targeting immediately, whether to disseminate it, or whether to send it for further analysis.

\subsection{Weaknesses in Building and Maintaining Situation Awareness}

We identified several weaknesses in the MEF's ability to build and maintain SA. One weakness was the number of layers of personnel, which seemed to slow down the process. However, this may have been an artificiality of the MEFEX. There were fewer layers in UFL exercise.

A second, and more disturbing problem, was the map displays. These were not conducive to achieving good SA. On the operations side of the BCC there were three separate maps for G3, G2, and Fires. This forced the officers to make a mental integration of information to understand the relations of friendly and enemy situations and fire support coordination measures.

Example: At one point the officers were looking at an enemy unit on the Intel map trying to decide whether to engage it with Marine aviation, but they could not tell if it was within the Battlefield Coordination Line (BCL) (in which case they could engage it without further coordination) or beyond the BCL (in which case they would have to coordinate with the JFACC). The BCL was plotted on a different map. According to many Marines in the BCC, one had to walk around and look at all of the maps and then try to figure out what was accurate and what was not. Furthermore, there were no times listed on the maps, so the users could not tell how current the data were. If there was a target shown, it was not clear if that target was still there. No single individual appeared to be responsible for the accuracy of the maps in the BCC, so there was no one to ask in case of confusion. No one knew the last time the map had been updated.

Example: The two Analysts were at the G3 situation map brainstorming a response to an enemy situation, talking about how to task friendly units. There were no enemy symbols on the map; 
they were working from memory. They seemed to have a pretty good idea of the enemy dispositions, but somebody without the analysts' SA would have been totally lost.

To add further confusion, there were different Intel maps in Combat Ops and Future Ops. These Intel maps did not always portray the same information, and required coordinated updating.

The issue of maps was a touchy one. Each section had special display requirements and could not be blamed for wanting a map on which to keep its own information. Thus, the G2 personnel wanted to write notes on their map and keep it informal as a working document, and they could not do that if $\mathrm{G} 3$ personnel were going to be using it.

Another weakness was the procedural approach to message flow. Thus, when messages were received regarding reactive fires, these were not sent electronically, but were printed out and put in an "in" basket for the targeting personnel to handle. At some points we found that there were about five requests sitting in the "in" basket. The procedure was being followed mechanically, without the sense of urgency needed to precipitate action.

At the same time, we found that a major weakness was the lack of appropriate procedures. Too many people were asking questions like, "What do I do with this?" "Who should I talk to?" "Who should get this mail message?" and so forth. Another worrisome sign was the lack of communication between people who were not sitting side-by-side. This situation seemed to call for a more integrated link between planning and execution.

We were also concerned about the BCC layout. Although it was a great improvement over the sharp separation between Intel and operations, the two functions were still not as integrated as they could have been. This was due to many factors. Nevertheless, progress was being made.

A few weaknesses were identified in the MEF's ability to derive inferences, which is a component of building situation awareness. The MEF had trouble routing Battle Damage Assessment (BDA) information. Considering the criticality of BDA, we would have expected a well-developed routine for collection, interpretation, and dissemination. This did not happen in at least one MEFEX that we observed. The problem may have been an artificiality of the exercise. Nevertheless, this does not explain the lack of procedures. Here was a case where procedures were necessary and seemed inadequate. One cannot checklist BDA; it is all contextual and requires interpretation, but procedures are needed to make sure it receives that interpretation. The $3^{\text {rd }}$ Marine Air Wing (MAW) owned the BDA, and knew the logic, but the BDA was not communicated and interpreted, even when it was available. The Analysts in the BCC needed BDA at their fingertips, to gauge who was most threatening and what their current strength was.

In this context, we noted the practice of hitting the same target, day after day, waiting for BDA. This procedure seems inefficient. If resources are limited, there might be some value in prioritizing the targets to be reattacked, versus those that can be deferred until BDA is obtained.

The problems with monitoring the progress of the battle did not prevent the MEF from deciding when to transition from one phase of the plan to the next. In an ideal world, the preconditions could be set, and then used as triggers for the transition. However, the MEF staff recognized that 
in an uncertain world, these triggers would not be reliable. The exercise of building preconditions is useful for learning, but few expected that the preconditions would be determined in a straightforward way. Instead, the decision about transitioning was largely intuitive. At the same time, the intuition has to be based on some evidence about the progress being made. The difficulty with BDA manifested itself here. The lack of clarity of the big picture made the decision about transitioning from one phase to the next more difficult than it should have been.

Example: There was much discussion about meeting the necessary preconditions to begin Phase II of the operation. The sense was that things were going more slowly than expected and Phase II would have to be delayed. On the second day, a lot of energy was devoted to figuring out how soon the conditions would be met. There was much concern that the MEF was "not getting good BDA" (although the Chief of Staff was eventually able to get the point across that this lack of feedback was part of the irreducible element of uncertainty and would have to be accepted and coped with). By the third day, the BDA was not any better, but the MEF had decided to initiate Phase II by 0900 the next day. The determining factor had become time. The supposedly inviolate preconditions were essentially discarded altogether in favor of the need to act quickly.

Another weakness was that the reporting of data appeared to be piecemeal, without any central picture to show overall trends. As a result, it was difficult to see the big picture, and to gauge the progress of the battle. This may have made it difficult for staff members to notice that events were not going as planned. One of our observers pinpointed this as the weakest area in the BCC's performance: the length of time it took for people to notice a breakdown in the plan, to replan, and to implement the new plan. It was not clear what form the big picture should take. Simple reporting of casualties or positions was inadequate, for reasons discussed above. The reporting of overall trends would likely be too vague. There was another challenge here, to develop a means for describing changes in the big picture.

A final weakness, in our opinion, was the lack of support to help the CG form his own picture. The map displays appeared inadequate for this purpose, requiring a fair amount of study to determine what was happening. The CG seemed to be put in a position where he had to depend on the briefings and interpretations of his staff, rather than being able to proactively form his own conclusions. This was time consuming and may have compromised his ability to use his own experience to make sense of events.

\section{Planning and Decision Making}

As we stated above, the MEF is a planning organization. Therefore, we began our observations in search of the planning process. What we found was perplexing. When we were in the $\mathrm{BCC}$, we were told by a high-ranking officer that the BCC does not do any planning. They only carry out plans. So we went upstream, to Future Ops. There we found that the plans generated were rarely used. We moved further upstream, to Future Plans, and heard the same frustration, about the time spent building plans that were usually not carried out, or used. Therefore, our initial impression was that little useful planning was going on, even though that was a key mission of the organization. 
We quickly realized that planning was taking place-not the waterfall approach shown parts (a) and (b) of Figure 1, but rather the approach shown in part (c) of Figure 1. The planning process is flowing in two directions at once. Some planning is top down, beginning with Future Plans. And some planning is bottom up, initiated in Current Ops. Both directions are essential.

We identified two classes of planning: deliberate planning and dynamic planning.

\subsection{Deliberate Planning}

The cognitive demand of deliberate planning, shown in Table 3, required the planners to anticipate how a mission was likely to proceed, to identify potential problems, and to systematically schedule resources and tasks to provide an efficient flow of operations.

Table 3

Cognitive Demands of Deliberate Planning

\begin{tabular}{lll} 
Why Difficult & Weaknesses & $\underline{\text { Strategies }}$ \\
\cline { 2 - 3 } Long-range vs. immediate needs & Over-specifying details & Future Plans and Future \\
Uncertainty & Over-proceduralizing & Ops \\
Need to set preconditions & Disconnects between cells & Battlespace Shaping \\
Safety & Inefficiencies in Future Ops & Matrix (BSM) \\
Lack of feedback regarding air & Lack of resources in Future Ops & \\
missions & Limited focus of Future Ops & \\
Constraints of air planning & Focus on BCC crowds out Future \\
cycles & Ops & \\
& Too many cells &
\end{tabular}

\subsubsection{Difficulties in Deliberate Planning}

Deliberate planning was difficult for many reasons. Immediate crises disrupted long-term plans. An example would be the targets needed to shape the battlefield for the follow-on missions that might take place in a few weeks. Despite their importance, these targets were often downgraded in favor of more immediate threats. Another difficulty was the uncertainty facing the planners in Future Plans and Future Ops. Schmitt and Klein [1999] have discussed the various aspects of battlefield uncertainty and how these affect the planning process. The uncertainty affects many aspects of planning, such as the need to define preconditions for each phase of the plans. Under uncertainty, these preconditions are difficult to establish.

Planning was further complicated by the lack of timely feedback about which air missions were actually going to be flown, from the list that was nominated. During the air tasking cycle, targets were deleted or postponed, or they were hit during the sorties because of weather or air defenses, and feedback was not always timely, further complicating the lives of the planners in the Force 
Fires cell. One estimate was that about one-third of the missions were diverted on the day of the sortie, and that feedback arrived a day or so later. This was true for the division as well; once targets were nominated, it was hard to find out which ones were sourced, so they didn't know what still needed to be attacked. For instance, in the deep battle, the MEF had nominated 69 targets, and only 8 of them were addressed on the ATO. But there was no immediate information about which ones were addressed on the next ATO, which had recently been flown. This information had to be sought out. Another source of difficulty was the need to tie the MEF's planning to the three-day air planning cycle. The time horizon of the MEF was typically within three days, and so the drill of nominating targets that would be relevant in three days was a burden because of uncertainty. Finally, the MEF needed to be concerned about safety issues on an uncertain battlefield, to avoid fratricide and to avoid civilian casualties.

One of the important developments in the MEF was the strategy of establishing separate cells for Future Ops and Future Plans. The intent had been to make sure that appropriate attention was given to the distant goals. Before these cells came into existence, the MEF was concerned with the current battle, and perhaps with the next mission, and therefore was sometimes unprepared for the long-range missions. The MEF was not taking the necessary steps to begin actions to prepare for long-range needs. By setting up a Future Plans cell, the MEF had become more sensitive to these needs, and maintaining a longer time horizon, and had become better at balancing immediate and long-range priorities.

\subsubsection{Weaknesses in Deliberate Planning}

We observed a number of weaknesses in the MEF's deliberate planning process. One weakness was in the tendency of Future Plans and Future Ops to over-specify details. Future Plans sometimes seemed to be attempting to predict the future, despite the massive amounts of uncertainty that would make such an enterprise useless. At one point, they had developed a plan for two weeks out, and it covered river crossings, seizing cities, and air attacks.

We believe that the concept of a Future Plans cell is a good one. The weakness was more in the implementation than the concept. This cell has to resist a common tendency to over-detail its plans. This cell has an important function, to reflect the long-term missions so that logistics flows can begin in time, so that coordination activities can be initiated, and so that shaping can begin. Future Plans can identify the locations that would favor the enemy, and begin operations for preventing the enemy from occupying those positions. Future Plans can determine favorable sites for artillery, which may take a while to establish, and which needs advance preparation. Future Plans can detect inconsistencies in concepts, such as wanting the same unit in two different locations at the same time, and can revise the concept to eliminate the problem. These are important functions of Future Plans as it builds a platform for plan development and subsequent detailing. If Future Plans tries to do the detailing itself, it may often be wasting its time. It will find that the plans it generates become obsolete, so that it loses credibility and motivation. And it will run the risk of having inadequate plans locked in, through a sunk cost process, in which people feel compelled to carry out a plan because of the effort that has gone into it. 
Another weakness was a tendency towards over-proceduralizing. Rather than trusting the judgment of the skilled personnel, the MEF sometimes appeared to be trying to figure out how those skilled Marines accomplished their tasks in order to publish these procedures for others to follow. The assumption we question is whether the procedures will help or hinder others who are skilled, and whether the procedures will transform Marines with less skill into highly-effective team members. Over-proceduralization could be a barrier because it interferes with the exercise of judgment, tends to slow down $\mathrm{C} 2$, and draws attention away from the effort to gain understanding or situation awareness and toward satisfying the mechanical requirements of the procedure.

We provide several examples of over-proceduralization: The deliberate planning process practiced in the Future Plans cell, the production of the Decision Support Matrix and overlay; and the deliberate targeting process. These complicated, mechanical execution systems stood in contradiction to the USMC doctrinal view of the complex, unpredictable nature of war and the need for intuitive judgment based on SA. These products were neither useful to, nor used by, the executors. The matrix listed all the NAIs, associated TAIs, and decision points with the various options at each decision point. The overlay showed the NAIs, TAIs, and decision points; it connected the instructions on the matrix with the map of the battlefield. The two had to be used as a unit, and together they were centerpiece products of the planning process. The idea was that the executors in the BCC would use these to guide their conduct of the operation (e.g., the enemy trips an NAI on the map, the Analysts look up the NAI on the matrix, which refers them to the corresponding decision point, which in turn gives them one or more actions to take, including to fire a certain TAI). The underlying principle was to plan all the BCC's decisions in advance. In essence the idea was to eliminate the need for judgment in the BCC. All judgments were made beforehand-during planning (this, of course, was based on the assumption that the planners have better judgment than the executors). In the end, practically every road intersection, avenue of approach, and key piece of terrain got plotted. There might be several dozen decision points, with potentially several different courses of action (COA) for each, and a like number of NAIs and TAIs. The overlay was a confusing mass of stars and circles, the logic of which was anything but intuitive to the user.

The idea that any group of planners, no matter how intelligent or diligent, could possibly anticipate all the ways a co-evolutionary system like a military operation could unfold and could then preprogram all the possible decisions ignores the complexity of war. It greatly exceeds the "limits of foresight and design" described in Marine Corps Doctrinal Publication 5 (MCDP5). The system was so complicated that it would actually interfere with SA. It had far too many elements to be understood. Instead, the user spent all his/her energies just trying to follow the mechanics of it. In defense of the planners who produce these, the exercise of developing these tools was probably a good learning process which explains why they embarked on it so energetically: it forced them to think through the various implications and interconnections of the situation; the more they learned-i.e., the deeper they get into the situation-the more complicated the matrix became. Unfortunately, although the process may have had learning value, the physical product was practically useless for execution and, of course, the executor who was given this product never even benefited from the learning process that took place during planning. 
Regardless of any rational arguments for or against, the matrix and overlay simply had little practical value. They simply were not used. At one point, the Current Ops representative to Future Ops had built the template and overlay, and had briefed it-and even he did not use it! The overlay spent most of the first three days of one MEFEX rolled up out of the way on the G2 situation map. It spent half a day missing and unnoticed in its absence. It spent the last three days rolled up, leaning against a wall in the corner of the BCC, again completely unmissed. On one occasion, no one in the BCC or Future Ops was able to locate the overlay; one of our observers was finally able to unearth it.

To be fair, some elements of the MEF did find the decision support overlay useful. One prominent example was the head of the G2, who noted that the Analysts in one of his cells used two overlays, and that the NAIs were of great value. We did not have an opportunity to spend any time in this cell.

The playbook was another tool that went unused. The playbook is a written record of the planning concepts, rationale for NAIs and TAIs, and so forth. The Future Ops cell prepared the playbook, as a tool for handing the plan over to BCC. The only time we saw it employed as an execution tool was on one occasion where there was some question about which subordinate unit was the main effort. Otherwise, the playbook was usually buried under other materials. The playbook did seem to have some utility for familiarizing newcomers into the BCC, but if that is to be its primary function, it needs to be organized differently.

One of the few tools that was highly acclaimed and used was the Battlespace Shaping Matrix (BSM). This was seen as very useful for distributing guidance about target priorities, so that the MEF could quickly react to targets that met the criteria. We suspect that the use of relatively inexperienced personnel in reactive targeting roles was probably what made the BSM so important. Further, the combination of inexperienced technicians and pre-defined criteria may have made the MEF less responsive to targets of opportunity that were important but did not fit the criteria. A challenge that remains is to develop methods that will more usefully provide the Future Ops learning experience for the BCC personnel.

A third weakness consisted of the disconnects between the cells. One of the functions of planning was to generate a plan, but another function was to learn about the battlefield while generating the plan. If the plan is sent forward, without the knowledge gained, then much of the planning effort is wasted. Too often in the MEF, this was true. As a result, the Marines in the BCC were not able to use the experience gained to carry out plans, and thus neglected some of the useful aspects of the plans that had been generated in Future Ops. We recognize that many of the transitions may have occurred between the Phase II and Phase III exercises, and that we may not have seen these; good exchanges and coordination may have occurred at this time. However, under operational conditions, the time to achieve transitions is likely to resemble the MEFEX and UFL more than the Phase II/Phase III periods, so our observations still have some validity.

A fourth weakness is an "inefficiency" in Future Ops. This stems from Figure 1. If the official job of Future Ops is reflected in the detailed planning of part (b), then other tasks, such as responding to needs from $\mathrm{BCC}$, are distractions. Yet, as we see in part (c), there was a strong need for Future Ops to respond to planning requirements identified by the BCC. The result was 
that these requirements were a source of high workload. To ensure that it could generate deliberate plans, the Future Ops staff developed the strategy of generating these plans as early as possible, sometimes days in advance of when they were needed. That way, if there were interruptions, these would not prevent Future Ops from doing its job. Unfortunately, by generating its deliberate plans days in advance, the result was an even greater likelihood that these plans would be overtaken by events, and be rendered obsolete. It is a mistake to plan too late, but it is also a mistake to plan too early.

A fifth weakness was that the focus of attention was on events in the BCC, and these diminished the role of Future Ops. Future Ops had too few staff members, and their experience tended to be too low, compared to the resources available in Future Plans and in the BCC.

\subsection{Dynamic Planning}

Often, the MEF has to improvise and react to events, either to problems or to unexpected opportunities. Dynamic planning is usually conducted under heavy time pressure and high levels of uncertainty. (See Table 4.) Moreover, there are usually a large number of elements to coordinate, making it difficult to formulate, evaluate, and implement the revised plan. This requirement for dynamic planning, which flows from the BCC to Future Ops rather than the other way around, is completely unrecognized in the Marine Corps Planning Process.

Table 4

Cognitive Demands of Dynamic Planning

\begin{tabular}{|c|c|c|}
\hline Why Difficult & Weaknesses & $\underline{\text { Strategies }}$ \\
\hline Time pressure & Slow to react to targets of & Analysis cell \\
\hline Uncertainty & opportunity & Battlespace Shaping Matrix \\
\hline Number of people to & Number of layers of people & $(\mathrm{BSM})$ \\
\hline coordinate & Wrong concept of planning & Informal cycle \\
\hline
\end{tabular}

At many points, we observed how the Future Ops cell was given a surprise task from the BCC, and a short timeline, and, using no formal procedures, they put their heads together well and generated a useful branch sequel or whatever was required. The downside was that this was interpreted as Future Ops being sucked into current operations in the BCC. Our view is the reverse. Future Ops was being used to generate reactive plans, to do what-if exercises into the future, to take advantage of their understanding of the future situation. Even when Future Ops found that the plan that the BCC wanted to press forward was not feasible (e.g., a certain road could not handle the level of logistics support required) the exercise was seen as useful in passing along knowledge to the Analysts in the BCC. 


\subsubsection{Difficulties in Dynamic Planning}

Dynamic planning is usually conducted under heavy time pressure, and high levels of uncertainty. Moreover, there are usually a large number of elements to coordinate, making it difficult to formulate, evaluate, and implement the revised plan.

Nevertheless, the MEF did a very good job of dynamic planning. One of the great strengths of the MEF for dynamic planning was the Analysis Cell in the BCC. This consisted of a few Marines, reservists, with high levels of competence and experience, and no administrative responsibilities. Their job was to track events and make adjustments.

At times, the Analysis cell seemed to be the central planning agent in the MEF, despite their position inside the BCC (which claimed not to do any planning at all). In one incident, the Chief Analyst reported to the G3 that "Intel indicates that enemy unit X is massing in this area, east of TAOR Eagle. We don't yet know their strength, but we know it's less than a brigade. It looks like they're preparing for a counter attack. However, this might be a good thing for us, because they are opening themselves up to air attacks." This was an important observation. But the time scale that the BCC was focusing on would suggest that this was a Future Ops interaction, not a BCC function. In cases such as these, the Analysts in the BCC appeared to be doing the job of Future Ops.

\subsubsection{Weaknesses in Dynamic Planning}

One weakness, discussed earlier, was the slowness to respond to targets of opportunity in the reactive targeting chain. This may have been a function of using less-experienced personnel, who needed to rely on materials such as the BSM (or, more accurately, the Attack Guidance Matrix derived from the BSM). Procedures and matrices are not a substitute for experience.

A weakness was the difficulty of figuring out what had changed after a plan had been modified. For example, when Future Ops developed a draft fragmented order (FRAGO) and sent it to the BCC, if the BCC made changes, they sometimes did not communicate those back to Future Ops. Only when the FRAGO was issued, and Future Ops was copied, did they learn of the changes, and then only by reading the FRAGO and comparing it to the original. In general, changes were issued as new directives, without showing how the previous directive had been altered.

\section{Information Management}

While the job of the MEF was to make plans and decisions, in order to achieve that goal it had to perform a number of enabling functions. One of these was to manage information flow, particularly so that the Marines were building and maintaining their SA of the battlefield. Two key agents were identified: distributing information and seeking information.

\subsection{Distributing Information}

One of the demands on the MEF was to efficiently distribute the information it had (see Table 5). The MEF used the traditional means of distribution, such as FRAGOs, operations orders, and so 
forth. It used maps and briefings. It was exploring the use of information technologies. Most of these themes have been discussed earlier (along with the corresponding weaknesses) and do not require additional commentary. But the themes need to be at least mentioned here because inefficiencies in distributing information can cripple the MEF in two ways. If this function was not performed well, then critical messages may not be sent to the right element at the right time. We saw instances during a MEFEX where a division CG was frustrated for an entire day because of a missing piece of information. Only at the end of the day was it discovered that the message containing this information had been sent, and was sitting, undelivered, in a pile of messages at the division $\mathrm{HQ}$.

Table 5

Cognitive Demands of Distributing Information

$\begin{array}{lll}\text { Why Difficult } & \text { Weaknesses } & \underline{\text { Strategies }} \\ \text { Requires mental models (e.g., } & \text { Briefing formats } & \text { Briefings } \\ \text { COC personnel roles and } & \text { FRAGO } & \text { Traditional forms } \\ \text { functions) } & \text { Maps } & \text { Maps } \\ & \text { Lack of procedures } & \text { Information technology } \\ & & \text { Significant Events board }\end{array}$

The second concern was the continuing proliferation of irrelevant messages. Indeed, most of the problem of information overload was properly a problem of excessive and undirected proliferation of low relevance messages. If the MEF was able to tighten up its procedures for distribution, the results could be valuable. The abuse of emails, discussed earlier, was a prominent example. If a key message was not sent, the failure could be traced and blame could be assigned. However, no one was ever blamed for sending an irrelevant message, and so the policy became, "when in doubt, send it out" and copies were distributed just in case anyone on the distribution list might be interested. The cost of distributing extra messages was low, compared to the cost of using verbal communications to keep people informed. So the growth of messages increased, and the efficiency of the MEF was reduced.

The MEF was continually taking steps to counter these concerns. For example, the Significant Events board, used in the BCC in UFL, appeared to be a success story. It was frequently accessed and updated. As a sign of its importance, it was updated by 06s, not by technicians. People entering the BCC frequently look at it to get an update.

\subsubsection{Difficulties in Distributing Information}

One reason information management was difficult was that effective dissemination required a rich mental model of the entire MEF COC, including an appreciation of the information needs of all the key personnel, as well as their roles and functions. Sometimes, this could be reduced to a checklist or a set of criteria. However, too often it required an ability to understand how a piece 
of information could be critical in helping someone else perform his/her job. Checklists were not a substitute for this type of understanding.

The briefing process exacted a penalty in terms of time and energy for preparation. If the MEF CG wanted a 1530 brief, the division CG had to be briefed first, and the brigade commander had to be briefed before him. The situation was worse for a small unit, such as the G3 Future Ops cell. This section was in the business of writing FRAGOs for future phases. It typically was staffed with only one planner (for the current exercise) and one officer who put together viewgraphs for briefings. The planner was extremely busy because he was continuously writing numerous branch plans for each operation. He appeared to actually spend more time preparing for and giving briefings than he did planning.

This level of effort would be reasonable if the payoff was high. But the great majority of briefings we saw at MEFEX were pro forma presentations rather than substantial working meetings. There were a few cases of disagreements about how to deal with some issue, and every once in a while someone would volunteer a candid and unsolicited opinion, but these instances were rare.

Some of the difficulties were due to a mechanical passing of messages, without time to revise for different audiences. Thus, a complaint from one of the divisions was that "the MEF sends down stuff that was in its original format and not written for our level and we have to stare and it and admit that I don't understand how this applies to me."

\subsection{Seeking Information}

The MEF did not simply collect, process, and disseminate information. It also took an active role in seeking information to meet its needs. Without this function, the MEF would be forced into a passive mode of trying to fit pieces together. By actively seeking information, the MEF could rapidly gain clarity on vital issues. Moreover, by actively seeking information, the MEF could avoid some of the information overload problems. The MEF did not need a high level of detail for everything that occurred within a 200-mile box. Instead, the MEF needed high resolution for limited areas of the battlefield. By defining those areas, it could get the resolution it needed without suffering the penalty of overload. The more precise and effective its information seeking, the smoother its overall information management. (See Table 6.)

Table 6

Cognitive Demands of Seeking Information

Why Difficult?

Complexity of system

Changes in situation collection

Missing information

Unreliable connections

Need for expertise
Weaknesses

Use of CCIRs

Restricted access to plan $\underline{\text { Strategies }}$

CCIRs

Collection plan 


\subsubsection{Difficulties in Seeking Information}

One difficulty was the sheer complexity of the overall system. The MEF had to work with a chaotic world, where the status of events and agents was continually changing, where information was often missing, and where connections were not reliable. Thus, there was little payoff in trying to find the location of an enemy air defense unit if it turned out that the unit was mobile, and if the resources for attacking it could not be mustered for a few days. There was little value in spending assets trying to locate the enemy's artillery if the enemy had done a good job of hiding these assets so that the likelihood of success was very low, considering the payoff. There was risk in depending on Intel from aviation if the weather was projected to be cloudy, reducing the quality of the Intel and possibly preventing the air sorties altogether.

It was difficult to know how to use the assets available to the MEF, including national assets but even the organic assets, their boundary conditions, and limitations. All of these had to be taken into account. For example, Unmanned Aerial Vehicle (UAV) technology offered some important breakthroughs, but the UAVs could not be depended upon if the wind velocity was too great. Information seeking has to take into consideration many details such as this.

As a result, effective information seeking required a high degree of expertise. The desired information had to be well understood (why it was important, and for how long, and in what form), and balanced against the assets. This was a classical resource allocation problem: how best to use the collection assets to achieve the goals. Thus, expertise was needed to gauge the likelihood that the collection effort would be successful, the value of the information to be gained, and the opportunity cost of the effort (i.e., the other opportunities that were neglected).

\subsubsection{Weaknesses in Seeking Information}

Two of the primary strategies the MEF used for information seeking were to issue Commander's Critical Information Requirements (CCIRs), and to build a collection plan for applying its assets. We identified weaknesses in the use of each strategy.

The concept of CCIRs was to enable the CG to identify the high priority data elements that he needed to obtain, so that the MEF could devote its resources to them. While the concept was important, the execution still needed to mature. One concern was that during the USMC exercised we observed, including MEFEX opportunities, the CCIRs tended to be defined in advance, and not to change during the course of the exercise. This suggested that the senior staff members were not using the CCIRs as a flexible mechanism to help them monitor the progress of the battle. Instead, they often appeared to be filling a box, and then ignoring the process. During briefings, we did not see any pressure to obtain responses to the CCIRs. And when information needed was identified, we did not see these get transitioned into CCIRs. Our conclusion was that the CCIR mechanism was not achieving much.

We believe that the CCIRs were being used within the G2 shop. We did not have the opportunity to observe that process. So we could not conclude that the CCIRs were ineffective, because we don't have the data or evidence to back up that claim. Further, there could have been different problems if the CCIRs were continually changing, creating confusion. Therefore, we must be 
cautious about our judgments here. Nevertheless, the fact that the CCIRs did not change in the one MEFEX we carefully observed for a week, indicates that they may not be used as a flexible and selective tool, and that a potential resource is capable of being significantly improved.

The problem may have been the procedures by which the CCIRs were being developed and pursued. Identifying CCIRs days in advance seems to be a way to freeze curiosity with a cumbersome bureaucracy. The problem may also have been a lack of familiarity. We observed an Army unit using CCIRs and Prioritized Information Requirements (PIRs), and found that they were taking them very seriously, and were working actively to provide the necessary data. Even 1MARDIV (Marine Division) seemed to be working harder on CCIRs than the MEF. This may have been an instance of a tipping point. Attention to CCIRs needed to reach a certain level so that they were pursued vigorously, which provides better inputs, which in turn increases the use and attention to CCIRs. Until that level of emphasis was reached, CCIRs could easily become one more task to get out of the way.

The second area of concern was about the collection plans. We did not have a good opportunity to observe these being developed and used, but we believe that collection plans were the heart of resource allocation for information seeking. At the MEFEX we saw a lack of proactivity regarding collection plans. That was, if the Analysts in the BCC had been able to see what collection assets were going to become active, it could have changed their thinking about how to revise plans. Without this capability to get ahead of the curve, the BCC and Future Ops staff members and others had to adopt a more passive role of accepting data that became available, rather than building plans to take advantage of data that was going to be available.

This observation from the MEFEX (about the lack of visibility of the collection plan) did not hold for UFL, where there was a serious effort to develop a graphic showing the targets covered with an area coverage overlay.

\section{Guidance}

The MEF had an important leadership role, to direct the actions of the Marines working inside the MEF, as well as those interacting with the MEF. This included a cognitive component because one of the ways the MEF exercised this leadership was by helping to build mental models. When the MEF builds a mental model of its intent and vision, it was called topsight. When the MEF coordinates the actions of others, it was building a mental model of their roles and functions so that each Marine knows what was expected of him/her, and, equally important, each Marine knows what to expect and how to support others.

\subsection{Provide Topsight}

This cognitive demand was primarily about communicating relevant information about the mission and the intent to subordinate units. (See Table 7.) 
Table 7

Cognitive Demands of Providing Topsight

\section{Why Difficult}

Time pressure for uncertainty notification $\underline{\text { Weaknesses }}$

Lack of procedures for emergency notification

Commander's intent approach $\underline{\text { Strategies }}$

Resource allocation strategies

Decentralize planning authority

Commander's intent approach

\subsubsection{Difficulties in Providing Topsight}

One problem here was time pressure. Example: Someone called into the BCC over an old radio net, giving SCUD launch information. The head of the BCC asked if the BCC had any procedures telling the Subordinate Commands about the SCUDs. Apparently, there were no procedures for carrying out this notification. The head of the BCC got on the nets and called 1MARDIV and 3MARDIV. Then he asked who had not been called, and was told that 1MAW and 3MAW still hadn't been notified. This illustrated the time pressure for providing guidance. It also illustrated the need to work out procedures in advance. The MEFEX appears to be the right place to discover these disconnects, and establish the procedures.

\subsubsection{Weaknesses in Providing Topsight}

The use of Commander's Intent statements was one of many methods for providing topsight. In our opinion, this tool was not being effectively used. The importance of the Commander's Intent statement was widely recognized throughout the MEF, to the point that it had taken on cultural significance. Its effective use was less well understood. The idea behind providing the intent behind a task was that when events changed to make the task obsolete (which the Marines trust would often happen), an understanding of the underlying intent would allow subordinates to undertake a new task on their own initiative to accomplish the original intent.

The intent statements seemed much too long. In one MEFEX, the intent was six pages long. There was too much guidance, and it was too unfocussed to be of much use in helping subordinates to exercise judgment. The kinds of information classified as intent included:

- Direction of attack

- Phases of the operation

- Desired end state

- Multiple intents such as "Destroy enemy in zone" and "Interdict Lines of Communication (LOCs)"

- Designated MEF and enemy critical vulnerabilities and centers of gravity

- Admonitions like: "Security was more important than speed," "Don't get focused too deep too early" (which have the same impact as admonitions to "Eat all your vegetables"). 
- Lists of separate instructions for each ground maneuver element (but not for Aviation Combat Element or Combat Service Support Element), to include: task, "IOT" (in order to) intent, and concept of employment for that unit.

There was a separate "Intent for Fires" that seemed to be independent of the overall intent. The "Intent for Fires" was really additional commander's guidance on the use of fires, but also there was additional material that was actually called "Commander's Guidance for Fires." The distinction between "Intent for Fires" and "Guidance for Fires" was unclear; the only difference seemed to be that the former was more urgent than the latter. There should only be one intent for the operation (assigned by higher HQ) and then the commander should assign a task and intent to each subordinate.

Furthermore, the Commander's Intent statement was not proactively used to signal shifts in the situation. In one case, the MEF staff (minus the CG) decided to shift to a more defensive posture to prepare for an attack from the north. But this was never disseminated as a revised Commander's Intent statement. And the CG's briefings did not cover Commander's Intent items.

\subsection{Clarify Roles and Functions}

In order to ensure effective coordination, it was essential that the Marines in the MEF understood their own roles and functions and those of the Marines with whom they would be coordinating. This required a good mental model of how the MEF was working, who did what, who needed what, why they needed it, and who could provide what. (See Table 8.)

Table 8

Cognitive Demands for Clarifying Roles and Functions

$\underline{\text { Why Difficult } \quad \underline{\text { Weaknesses }} \quad \underline{\text { Strategies }}}$

Rate of turnover

Complexity of the MEF

Changes in procedures

Liability to tunnel vision

Exercises

Substitution of procedures for Instructional materials

functional understanding

\subsubsection{Difficulties in Clarifying Roles and Functions}

This was difficult because the MEF experiences a continual turnover, and uses augmentees and reservists in key positions. Moreover, the MEF was far more complex than other USMC command posts, with greater differentiation of cells and functions. Finally, the MEF continues to adapt and revise its organization, in trying to improve operations; this was an important function but it created difficulties in developing instructional materials that might quickly become obsolete. 
The MEF used some instructional materials, and MAGTF Staff Training Program was an important source of guidance and training. In addition, the MEF relied on exercises such as the MEFEX and UFL to help the participants understand how to work together.

\subsubsection{Weaknesses in Clarifying Roles and Functions}

There was a central core of officers who understood how the MEF worked, and how to get things done. There was also a large periphery that was composed of people quietly doing their jobs with a limited mental model of how that job fit into the overall picture. Paradoxically, some of the supports provided to those on the periphery, the procedural guidelines and checklists and matrices, permitted them to work effectively without having to formulate a rich mental model; the result was that the supports helped them be productive while inhibiting their learning. The result was a high degree of tunnel vision.

One of the reservists who did seem to form a good mental model said that, "The BCC was a much larger scale than, for example, a battalion COC in which you can just look over the Intel guy's shoulder to see what his situation was, or listen in on his conversation to know what he's dealing with. Keeping SA in the BCC was much more difficult because of the large number of people and the large space."

The other side was revealed during UFL, when one of the Analysts realized that among the primary MEF cells, no one really knew what the other cells did. As a result, they set up a meeting with a key player from each of the major cells for an information exchange. Each Marine spent about 15 minutes giving an overview of what each cell did and was responsible for. Several people appeared to be surprised at what everyone else was saying. The meeting lasted about two hours. It speaks well of the MEF that they could see the need for such a session; but it suggested the need for building mental models earlier in the process.

The confusion about roles and functions, and the weaknesses of mental models, was shown in the ways people did not understand the basic procedures. Too many people were asking questions like, "What do I do with this?" "Who should I talk to?" "Who should get this mail message." Another sign was the lack of communication between people who were not sitting side-by-side.

Example: A Fires officer received a message from 1MARDIV relaying the location of an enemy unit. He asked the Force Fires coordinator, "Do I need to tell anyone else?" Clearly, this officer did not understand the relevance of information to others, because he did not understand their roles and functions.

During much of the MEFEX, people wandered into the BCC and talked about situations and resolved problems and then moved on. A few minutes later, different people wandered in, discussed the same problem, solved it in a different way, and moved on. There was no understanding of who to report to and how to coordinate these discoveries.

Example: A Direct Air Support Center (DASC) representative popped into the Future Ops meeting. He was getting calls about specific numbers of sorties required for the next couple of 
days. The Tactical Air Command Center (TACC) was calling DASC for specifics. They didn't know where to go for information. In turn, DASC didn't realize that, once this information was worked out in Future Ops, it was passed to the BCC. This happened frequently. Marines came to Future Ops to find out how plans were progressing, but they should have gone to the BCC.

\section{Conclusions}

The MEF is a highly complex organization, with many functions. In this paper, we could only discuss a few of the command and control functions that we were able to study. Moreover, our conclusions were based on observations from the time period of 1996-1998, so it is possible that the MEF has resolved the problems we identified.

We need to state how impressive the MEF operation was. Although we have primarily discussed weaknesses as a means of identifying areas where improvement was possible, our overall judgment was that the MEF staff worked hard to achieve effective coordination. Many of the staff members were experienced and competent, and were able to guide the MEF through its learning curve. They developed useful procedures, and they found ways to work around inefficient procedures.

We recognize that the MEF would require some level of proceduralization, or else the result would be chaos and confusion. For that reason, Schmitt and Klein [(Schmitt \& Klein, 1999a; 1999b) developed and presented a Recognitional Planning Model. This was a procedure for deliberate planning that would match more closely the constraints placed upon the MEF, and would still serve as a common frame of reference for staff members. Rapid turnover in the MEF reduces experience level, and creates a requirement for some form of proceduralization.

Our perspective, in the Recognitional Planning Model and in the comments presented in this paper, is to support the expertise that already exists in the Marines who make up the MEF, and to expedite the development of expertise during MEF preparations and exercises. The strength of the Marines is in its personnel, and no degree of proceduralization or information technology can substitute for that.

\section{References}

Klein, G., Schmitt, J., McCloskey, M., Heaton, J., Klinger, D., \& Wolf, S. A decision-centered study of the regimental command post. (Final Contract USC P.O. 681584 for the Naval Command, Control and Ocean Surveillance Center, San Diego, CA). Fairborn, OH: Klein Associates Inc., 1996.

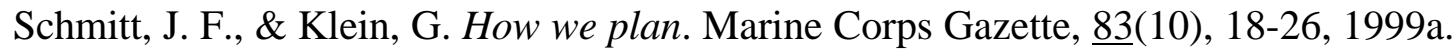

Schmitt, J., \& Klein, G. A recognitional planning model. Proceedings of the 1999 Command and Control Research and Technology Symposium (Vol. 1, pp. 510-521). Newport, RI: Naval War College, 1999b. 


\section{Acknowledgements}

We would like to thank General Tim Donovan and Colonel Bill Powers for their invaluable assistance in carrying out this program of research when they were at the MAGTF Staff Training Program (MSTP). General Paul Van Riper (retired) and General John Goodman provided the initial direction and requirement to study the MEF's decision making. The opinions presented in this paper reflect the judgments of the authors, and in no way represent any of the attitudes of Generals Donovan, Van Riper, or Goodman, or Colonel Powers, or official USMC policy. Rob Hutton provided useful editorial comments. 